|| ISSN(online): 2589-8698 || ISSN(print): 2589-868X ||

International Journal of Medical and Biomedical Studies

Available Online at www.ijmbs.info

NLM (National Library of Medicine ID: 101738825)

Index Copernicus Value 2019: 79.34

Short Review

Volume 5, Issue 6; June: 2021; Page No. 10-11

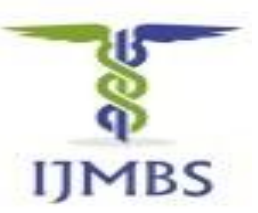

\title{
AUDITORY REACTION TIME MEASUREMENT WITH OBSERVER-BASED PSYCHOPHYSICAL PROCEDURE
}

\author{
Yasam Yildirim Baskurt', Gunay Kirkim² \\ Article Info: Received 13 April 2021; Accepted 30 May 2021 \\ DOI: https://doi.org/10.32553/ijmbs.v5i6.1934 \\ Corresponding author: Yasam Yildirim Baskurt \\ Conflict of interest: No conflict of interest.
}

${ }^{1}$ Dokuz Eylul University, Health Sciences Institute, PhD Student (https://orcid.org/0000-0001-7749-5791)

${ }^{2}$ Dokuz Eylul University, Health Vocational School, Prof. Dr. (PhD) (https://orcid.org/0000-0003-4170-5317)

\begin{abstract}
Reaction is defined as a behavioral response to a stimulus. The stimulus can be auditory or visual. Reaction time (RT) is determined as the time between the onset of the stimulus and response. According to this definition, the auditory RT is the time between the auditory stimulus and the response. Simple reaction time has been the subject of comparison of many different groups with both auditory and visual stimuli. When the simple auditory and visual RT in normal hearing individuals are compared, it has been observed that the auditory RT is faster than visual reaction. Auditory RT in womens's was observed slower than men. In many different studies, average values are 180-200 ms for visual RT and 140-160 ms for auditory RT with normal hearing and sighted individuals.
\end{abstract}

Keywords: Reaction Time, Cochlear Implant, Hearing loss

\section{Introduction}

Reaction is defined as a behavioral response to a stimulus. The stimulus can be auditory or visual. Reaction time (RT) is determined as the time between the onset of the stimulus and response. According to this definition, the auditory RT is the duration between the auditory stimulus and the response to stimulus ${ }^{1}$.

Simple RT has become a topic that has been addressed by medicine, disability assessment, environmental safety and sports branches in past years. Simple auditory reaction RT fastest reaction in humans ${ }^{2}$. Several factors affecting RT, and these factors are sensing the stimulus by the peripheral organ, converting the stimulus into neural signals, neural structures processing these signals, muscle activation, soft tissue resistance and measurement parameters.

One of the questions asked by sports sciences for the branch of athletics in the past is "what is the minimum reaction time value?". The answer to this question is directly related to the reflex arc known as the startle reflex, which mostly uses by audiology science in infants hearing evaluations. In order to understand the minimum RT for startle reflex, we need to know the sound transmission time in the components of the reflex arc. The time between the perception of the stimulus by the inner ear and its arrival to the brainstem is about $10 \mathrm{~ms}$. Afterwards, the time for the signal continuing from the reticular formation of the brainstem to reach the reticulospinal cord and from there to the spinal region is about $50 \mathrm{~ms}$. Assuming that the time for the response to find mechanical action in muscle tone is 15$20 \mathrm{~ms}$. Therefore the minimum time for the startle reflex is in the range of $75-80 \mathrm{~ms}$. Finally, when the $3 \mathrm{~ms}$ time for the sound to travel one meter distance is added to this, a total value is $78-83 \mathrm{~ms}^{3}$.

Simple RT has been the subject of comparison of many different groups with both auditory and visual stimuli. When the simple auditory and visual RT in normal hearing individuals are compared, it has been observed that the auditory RT is faster than visual reaction. Auditory RT in womens's was observed slower than men. In many different studies, average values are 180-200 ms for visual RT and 140-160 ms for auditory RT with normal hearing and sighted individuals ${ }^{1}$.

One of the first steps of audiological evaluation in infants is to observe the startle reflex and to start hearing evaluation according to the presence of it. Like the startle reflex, auditory RT can be an important data for pediatric hearing assessment. It has also great importance in monitoring pediatric audiological assessment, especially during visual reinforcement audiometry measurements. RT measurements are used with different methods to improve measurement techniques or determine the benefit of the hearing devices.

\section{The observer-based psychophysical procedure}

The observer-based psychophysical procedure (OPP) is a technique that can provide various information about children during hearing tests or other audiological evaluations ${ }^{4}$. OPP, developed by Werner et al. is an advantageous techniques for obtaining behavioral data from normal hearing children ${ }^{5}$. In the OPP procedure, whether or not the signal was presented according to the children behavior its determined by a trained observer. OPP also 
helps clinicians to evaluate most of the psychoacoustic ability, including perception, discrimination, localization, and classification in very young children. In recent study Grieco-Calub et al. (2008) used OPP to determine localization ability in children with cochlear implant (CI) ${ }^{6}$.

The ability to perception and orientation of sound decreases with the presence of hearing loss. This situation causes longer RT for hearing loss individuals than normal hearing individuals at the threshold and supra-threshold levels. Several methods are available to test CI infants and children, OPP seems well matched to obtaining RT data from infants.

In order to perform these evaluations, it is necessary to be a mastered pediatric audiological measurement methods and to know which one is more compatible with OPP. The OPP procedure is most suitable for the coordinated head-turn procedure. Its also known as visual reinforcement audiometry (VRA). In these technique infants learn to turn their head toward the reinforcer when they hear a sound. During the test, the response to sound is the turning of the head to the reinforcer. Therefore, it is also defined as the time diffrence between the onset of stimulus and the baby's head movement.

\section{Conclusion}

There is a relation between stimulus level and RT in children with CI. On the other hand, statistic data needs to extend with more participants. In many studies, RT times for identified decibel sensation levels can be an efficient clinical data in evaluating CI efficiency for children. The OPP technique may be adopted by clinics and used as an assessment tool for CI users in the rehabilitation process.
Clinical research into the RT of children with CI will illuminate on the future in revealing the deeper implications of this data. Because as we mentioned in the introduction of this mini-review, RT actually has a direct relation with a reflex arc containing deep sensation.

\section{Referances}

1. Jain A, Bansal R, Kumar A, Singh KD. A comparative study of visual and auditory reaction times on the basis of gender and physical activity levels of medical first year students. Int J Appl Basic Med Res. 2015 May-Aug;5(2):124-7.

2. Bazilinskyy P, Winter J. Crowdsourced Measurement of Reaction Times to Audiovisual Stimuli With Various Degrees of Asynchrony. Hum Factors. 2018 Dec;60(8):1192-1206.

3. Pain MT, Hibbs A. Sprint starts and the minimum auditory reaction time. J Sports Sci. 2007 Jan 1;25(1):79-86.

4. Olsho L, Koch E, Halpin C, et al. An observer-based psychoacoustic procedure for use with young infants. Dev Psychol. 1987; 23:627-640.

5. Werner, LA. Observer-Based Approaches to Human Infant Psychophysics. In: Dooling, R.; Fay, RR.; Klump, G.; Stebbins, W., editors. Methods in Comparative Psychoacoustics. Basel: Birkhäuser Verlag; 1995.135-146.

6. Grieco-Calub TM, Litovsky RY, Werner LA. Using the observer-based psychophysical procedure to assess localization acuity in toddlers who use bilateral cochlear implants. Otol Neurotol. 2008 Feb;29(2):235-9. 